\title{
Pyrolysis-Gas Chromatography Combined with SIMCA Pattern Recognition for Classification of Fruit-bodies of Some Ectomycorrhizal Suillus Species
}

\author{
By B. SÖDERSTRÖM, ${ }^{1 *}$ S. WOLD ${ }^{2}$ AND G. BLOMQUIST ${ }^{3}$ \\ ${ }^{1}$ Department of Microbial Ecology, University of Lund, Ecology Building, Helgonavägen 5, \\ $S-22362$ Lund, Sweden \\ ${ }^{2}$ Research Group of Chemometrics, Institute of Chemistry, Umeå University, \\ S-901 87 Umeä, Sweden \\ ${ }^{3}$ National Board of Occupational Safety and Health, Department of Occupational Health, \\ $S$-901 85 Umeä, Sweden
}

(Received 9 September 1981; revised 15 December 1981)

\begin{abstract}
Naturally grown fruit-bodies of Suillus luteus, $S$. bovinus and $S$. variegatus were subjected to Py-GC. The pyrograms obtained were statistically analysed and classified with a multivariate classification program (SIMCA). The class describing the $S$. bovinus pyrograms was significantly separated from both the $S$. luteus and the $S$. variegatus classes, while these two classes showed some over-lapping which was due to variation between different fruit-bodies within each species. The taxonomic significance of the statistical distances between the classes representing the species is uncertain.
\end{abstract}

\section{INTRODUCTION}

Thermal degradation of biological material by pyrolysis and the subsequent analysis of the degradation products by gas chromatography or mass spectrometry has for some years been used to produce 'fingerprints' of the material (Jones \& Cramers, 1977; Drucker, 1981). The most successful method for analysing the pyrolysis products seems to be by mass spectrometry. However, since a mass spectrometer is an expensive and complicated instrument a gas chromatograph is more attractive for the normal microbiological laboratory.

There are a number of reports on Py-GC of micro-organisms, viruses (Marais \& Kotzé, 1979), bacteria (Emswiler \& Kotula, 1978; Stern et al., 1979, 1980; Symuleski \& Wetzel, 1979; French et al., 1980; Gutteridge et al., 1980; O'Donnell et al., 1980; Abbey et al., 1981) as well as of fungi (Brosseau \& Carmichael, 1978; Gunasekaran et al., 1979; Blomquist et $a l ., 1979 a, b, c$; for earlier references see Drucker, 1981). However, in most of the earlier reports, the pyrograms were analysed only by visual comparison with one another. For classification purposes, quantitative data analyses are essential. MacFie et al. (1978) and Blomquist et al. (1979a) described two data analysis methods for Py-GC data which permit proper classification of the pyrograms (Blomquist et al., 1979b; French et al.. 1980; Gutteridge et al., 1980; O'Donnell et al., 1980).

In this paper we report a study of Py-GC combined with pattern recognition of fruit-bodies of three species of Suillus. Two of the chosen species are very closely related, and Singer (1975) classified them as belonging to the same section of the genus Suillus (section Fungosi Sing.). The third species belongs to another section of the same genus.

One important practical application of a classification based on pyrolysis would be the classification of sterile fungi in pure culture. An even more interesting application would be the classification of ectomycorrhizal fungal mycelium in situ Dominik (1959) and Zak 
(1973). Pg-GC was proposed for such purposes by Seviour et al. (1974), but high experimental variability in their results rendered the method inapplicable. Better data analysis techniques now available make the method worthy of further study. All biological material sampled in the field exhibits enormous variability, not only as a result of different strain characteristics but also due to varying environmental conditions during growth. In order to study this natural variability and to investigate the potential of $\mathrm{Py}-\mathrm{GC}$ for classification of such heterogeneous natural material, fruit-bodies of the three selected species were picked at different sites on different occasions.

The present data are not suitable for the development of a classification method of general application. For instance, the ageing of gas chromatography columns and variation between analytical instruments etc., necessitates the inclusion of reference samples in the analyses and a correspondingly more involved data analysis. These problems will be dealt with in future articles; presently we wish to demonstrate only the possibility of using Py-GC combined with SIMCA pattern recognition to differentiate between and to classify fungal tissue of naturally grown ectomycorrhizal fungi.

\section{METHODS}

Organisms. Fruit-bodies of Suillus luteus (L. ex Fr.) S. F. Gray, S. variegatus (Fr.) O. Kuntze and S. bovinus (L. ex Fr.) O. Kuntze were sampled during autumn 1979 in Scots pine (Pinus silvestris L.) forests in South and Central Sweden. When more than one fruit-body was picked in the same forest, specimens growing far away from each other were taken. Thus, all fruit-bodies sampled probably represent different mycelia. A few hours after sampling, the fruit-bodies were frozen and lyophilized after which they were stored at room temperature until analysed.

Preparation of samples. Samples of the lyophilized stipes of the fruit-bodies were ground in a mortar to a very fine powder. The powder was suspended in carbon disulphide $\left(2.5 \mathrm{mg} \mathrm{ml}^{-1}\right)$ and the suspension was homogenized in an ultrasonic water bath. Six, three and two fruit-bodies of $S$. luteus, $S$ variegatus and $S$. bovinus, respectively, were analysed.

Pyrolysis. Pyrolysis was carried out with a CDS 120 Pyroprobe (Chemical Data Systems, Oxford, Pa., U.S.A.) with a calibrated $\mathrm{Pt}$-ribbon pyroprobe. The $\mathrm{CS}_{2}$-suspension $(4 \times 20 \mu \mathrm{l})$ was applied on the cleaned ribbon with a micropipette, the $\mathrm{CS}_{2}$ was allowed to evaporate and the ribbon was flashed once $\left(100^{\circ} \mathrm{C}\right.$ for $\left.1 \mathrm{~s}\right)$. The probe was installed close to the column in the injector of the chromatograph. Pyrolysis was carried out in a stream of carrier gas (nitrogen). The final temperature was set to $600^{\circ} \mathrm{C}$, the ramp control was not used and the interval control was $20 \mathrm{~ms}$. The maximum temperature was reached in approximately $8 \mathrm{~ms}$ and was kept there for approximately $12 \mathrm{~ms}$. These pyrolysing conditions minimize secondary degradation of the primary thermal degradation products. After a chromatogram had been finished the ribbon was cleaned by heating in air at more than $1000^{\circ} \mathrm{C}$.

Chromatography. Analysis was made with a Perkin-Elmer 900 gas chromatograph equipped with a flame-ionization detector. A glass column $(3.0 \times 0.04 \mathrm{~m})$, packed with $10 \%$ Carbowax $20 \mathrm{M}$ on 100-120 mesh Chromosorb W AW DMCS, was used. Injection temperature was $100^{\circ} \mathrm{C}$ and the detector temperature $200^{\circ} \mathrm{C}$. The oven temperature was programmed for an initial hold for $6 \mathrm{~min}$ at $70^{\circ} \mathrm{C}$ after which the temperature rose to $150^{\circ} \mathrm{C}$ at a rate of $4{ }^{\circ} \mathrm{C} \mathrm{min}-1$ and was kept there for $30 \mathrm{~min}$. Each run was terminated with $170^{\circ} \mathrm{C}$ for at least $10 \mathrm{~min}$ to clean the column from high temperature boiling compounds. Carrier gas (nitrogen) flow rate was $40 \mathrm{ml}$ $\min ^{-1}$.

Data collection and treatment. Four to six pyrograms were collected from each fruit-body. Since the magnitudes of the peak heights were very different, two recorders with different recorder amplifications were used in parallel to enable measurement of all peaks. The pyrograms were digitized by measuring the heights of 49 peaks that could be found in all pyrograms. The baseline was drawn horizontally from the starting point of each pyrogram (Blomquist et al., 1979a). Examples of pyrograms, with some of the used peaks labelled, are shown in Figs 1-3. The data were analysed with a SIMCA pattern recognition program (written in BASIC and obtainable from S. W.) on a personal computer (ABC-80, Luxor-Scandia Metric, Stockholm, Sweden). The 32K, 8 bit, ABC-80 computer has the capacity to analyse simultaneously data sets with 2000 data elements, corresponding to, for example, 100 objects with 20 variables or, as in the present data set, 40 objects with 49 variables. Since the SIMCA analysis is made disjointly for each class, the data set may include many classes with each containing 2000 (or fewer) data elements. SIMCA also exists in Fortran for larger computers. The basis of the SIMCA method for classification is to approximate the data of each class ( $=$ species) by a separate principal components model. New pyrograms can then be classified according to their degree of fit to the different class models using linear multiple regression.

A principal components analysis was made on a sample of the whole data set (the whole data set $=57$ objects each with 49 variables). The sample was taken so that three fruit-bodies represented $S$. luteus and the other two 


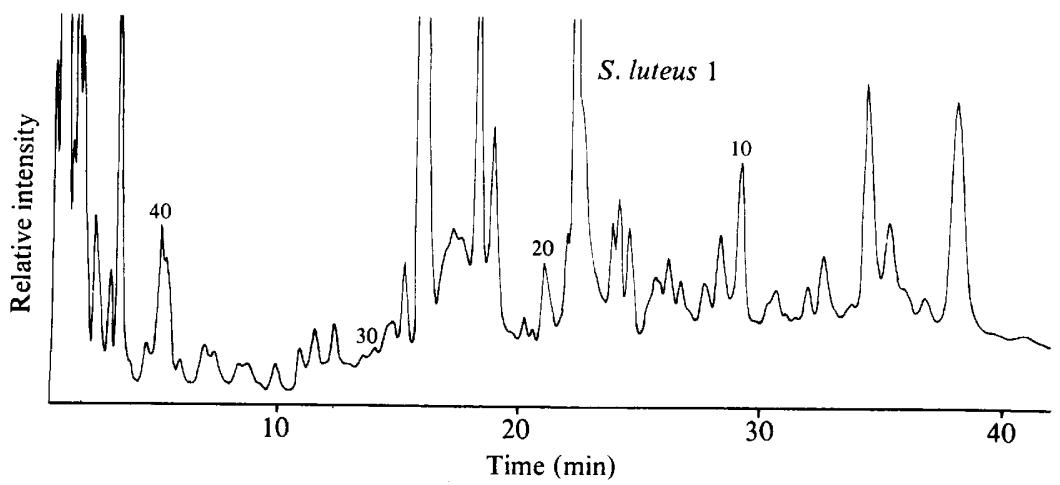

Fig. 1. A typical pyrogram of $S$. luteus with some peaks used in the analyses indicated.

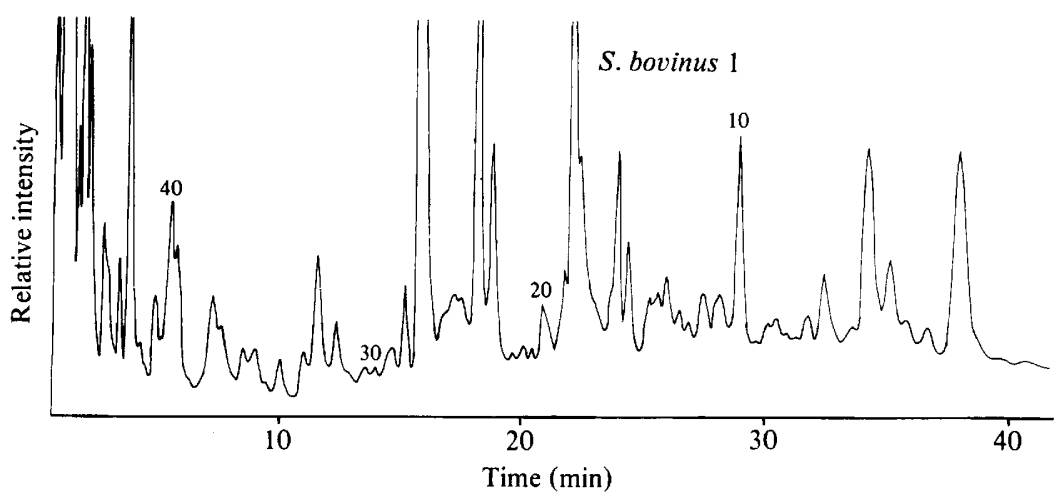

Fig. 2. A typical pyrogram of $S$. bovinus with some peaks used in the analyses indicated.

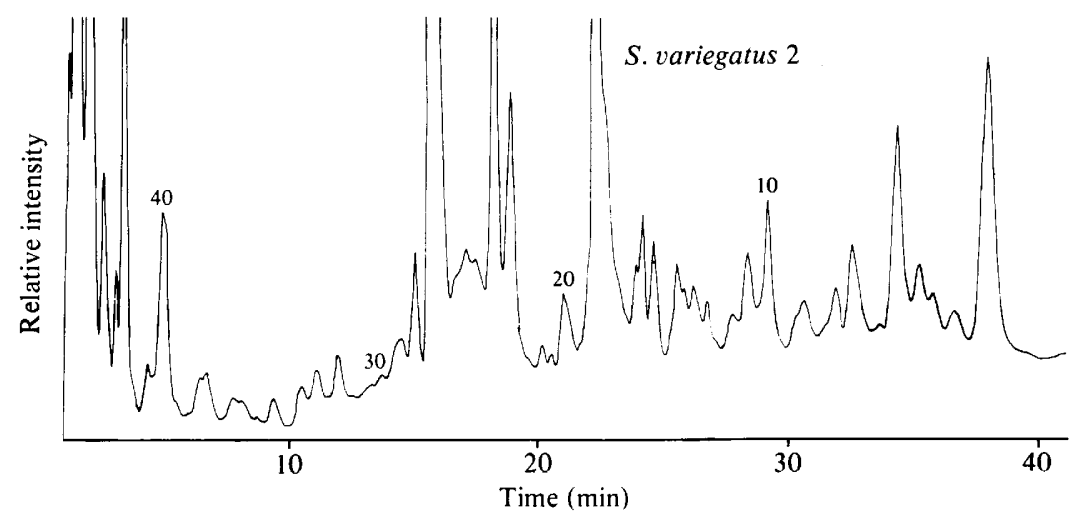

Fig. 3. A typical pyrogram of $S$. variegatus with some peaks used in the analyses indicated.

species were represented by three and two fruit-bodies, respectively. The results were very similar if samples were taken in another way.

For the SIMCA analysis separate models were calculated for each of the three species studied according to the description given, e.g. by Wold \& Sjöström (1977) and Albano et al. (1980). Below, the equations used will be referred to using the numbers given by Blomquist et al. $(1979 a)$. The models are based on principal components of the pyrograms of each species. In this analysis each class was separately scaled (Albano et al., 1980). The number of significant components in each class model was determined by cross validation (Wold, 1978). 
The variation of the data sets, which is not described by the models, is measured in a SIMCA analysis by the residual standard deviation, a model-S.D. (Equ. 2 in Blomquist et al., 1979a). Model-S.D. values were calculated for the three class models. Then, the pyrograms from all the fruit-bodies were fitted to the calculated models. This resulted in an object (= pyrogram)-S.D. value for each separate pyrogram (Equ. 4), in relation to each separate model. It is then possible by $F$-tests to decide whether the object in question significantly deviates from a particular model or not. If an object included in the calculation of a model turns up to give a high s.D., i.e. not belonging to the model, we may call this object an outlier of the class.

The distances between the different classes (Equ. 6) were also calculated using the class models and object-s.D. mentioned above. To obtain class limits which correspond better to the predictive value of the models, the models can be validated by an object validation procedure. One or a few objects are excluded each time, the class model is recalculated and the excluded objects are again fitted to the new model. The deletion is rotated over the whole class data set and for each deletion new models are calculated. This validation method is a conservative method, giving a class-S.D. and class confidence limits which are considerably larger than when all objects are included in the calculation, but it also gives a fairer description of the predictive value of the data.

Object validation was made of the present data in the following way: the $S$. luteus data set was validated by excluding the five pyrograms of one fruit-body at a time (i.e. a fruit-body was considered as an object). This means that six new models were calculated. The data in all these models were all identically scaled. The excluded pyrograms were reclassified and the resulting object-S.D. values were used for calculating a new class-S.D. The $S$. variegatus pyrograms were validated in the same way. Since the $S$. bovinus data set only included two fruit-bodies, this biologically strict validation procedure could not be used. Instead one pyrogram at a time was excluded.

The pyrograms were also analysed with a nearest neighbour method or single linkage clustering (Sneath \& Sokal, 1973).

\section{RESULTS}

\section{Pyrolysis}

The pyrograms of the different species appeared similar (Figs 1, 2 and 3). The first order reproducibility of the peaks of each fruit-body was fairly good. The mean coefficient of variation of the peak heights ranged between 8 and $20 \%$ for the different fruit-bodies. The peak coefficient of variation for each fruit-body was less than $10 \%$ when only the 20 peaks with the highest reproducibility were used.

\section{Principal components analysis}

In spite of the standardized way the samples were applied on the probe of the pyrolyser, the samples did differ significantly in size. Since the data were not normalized prior to analysis, the first component in the principal components analysis therefore mostly describes the size variation in the samples. This was seen by comparing results from normalized and unnormalized data, but the size factor may also appear in other components. However, the subsequent components will mainly describe other heterogeneities in the data sets.

The second and third principal component obtained in the PC analysis of the whole data set are plotted against each other in Fig. 4, while components three and four are plotted in Fig. 5. Suillus bovinus appears well separated from $S$. luteus and $S$. variegatus. When the principal components were calculated for the classes $S$. bovinus $+S$. luteus (Fig. 6) and $S$. bovinus $+S$. variegatus (Fig. 7) separately, this separation seemed confirmed. The situation appears somewhat more complex when the relations between $S$. variegatus and $S$. luteus are analysed. In Fig. 4 the separation between these fungi appears in part to be poor; $S$. luteus 1 appears to be rather similar to $S$. variegatus. A plot of the third and fourth components of the whole data set (Fig. 5), looks better. Figure 8 shows the second and third principal components counted for the class $S$. luteus $+S$. variegatus. Here a separation seems possible.

Thus, from the plots of the principal components of data including several species, it appeared that the pyrograms of $S$. bovinus clearly differed from those of $S$. luteus and $S$. variegatus. The pyrograms from these two latter fungi also appeared different, but showed some overlapping. 


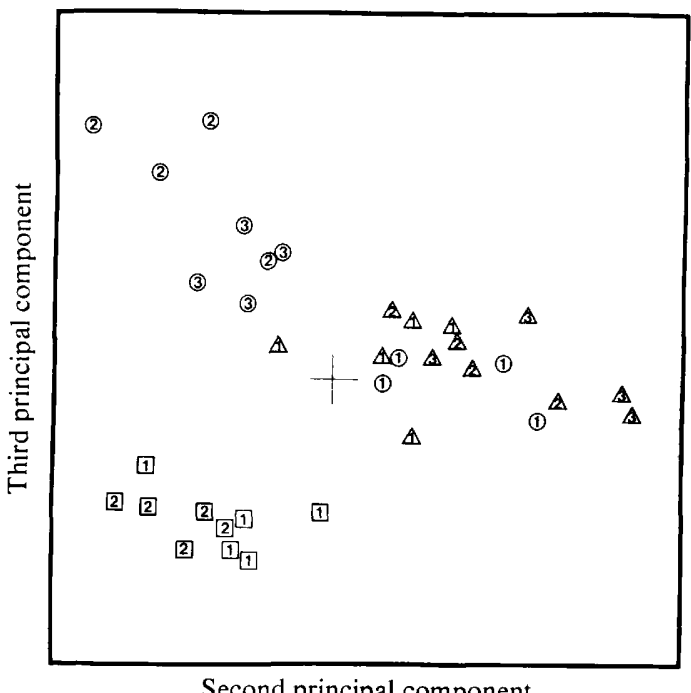

Fig. 4. The second and third principal component plotted after a principal components analysis of a sample of fruit-bodies of three Suillus species. Circles, $S$. luteus; triangles, $S$. variegatus; squares, $S$. bovinus. The numbers in the symbols refer to the fruit-body number within each species.

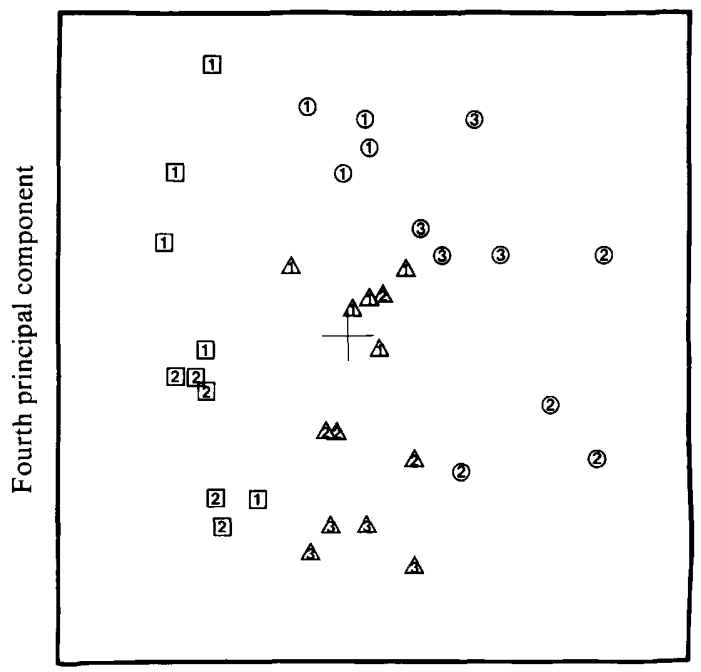

Third principal component

Fig. 5. The third and fourth principal component after the same principal components analysis as referred to in Fig. 4.

\section{SIMCA analysis}

The class model (Equ. 1 in Blomquist et al., 1979a) for $S$. luteus was based on three significant components $(A=3)$. These three components together explained $90 \%$ of the variation in the data. This includes the variation due to sample size. The $S$. bovinus model was also based on three significant components, explaining $96 \%$ of the variation. In the $S$. variegatus model the number of significant components was two $(A=2)$. These components explained $88 \%$ of the variation. In all three models six variables (= peaks) were omitted, since they contributed very little information to the models. Only one of the deleted variables was common to all three models. 


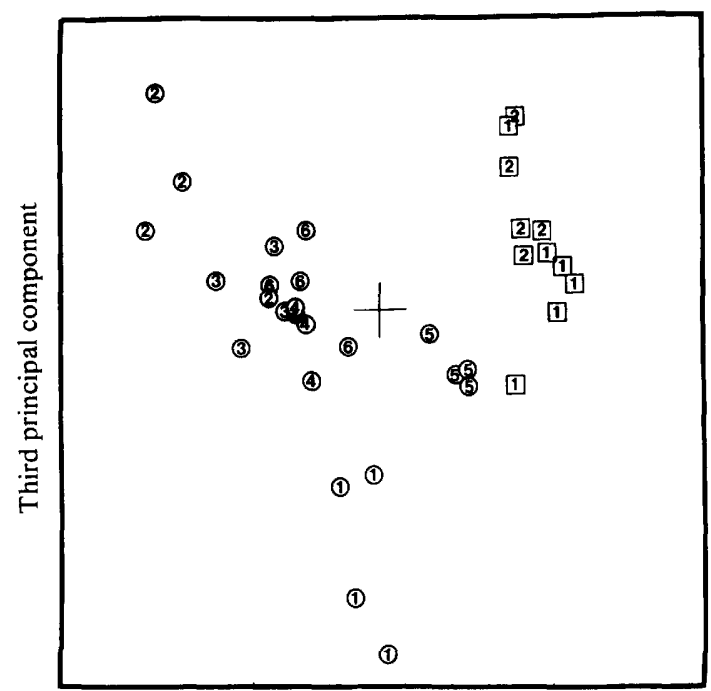

Second principal component

Fig. 6. The second and third component plotted after a principal components analysis of pyrograms of $S$. luteus (circles) and of $S$. bovinus (squares). The numbers in the symbols refer to the fruit-body number within each species.

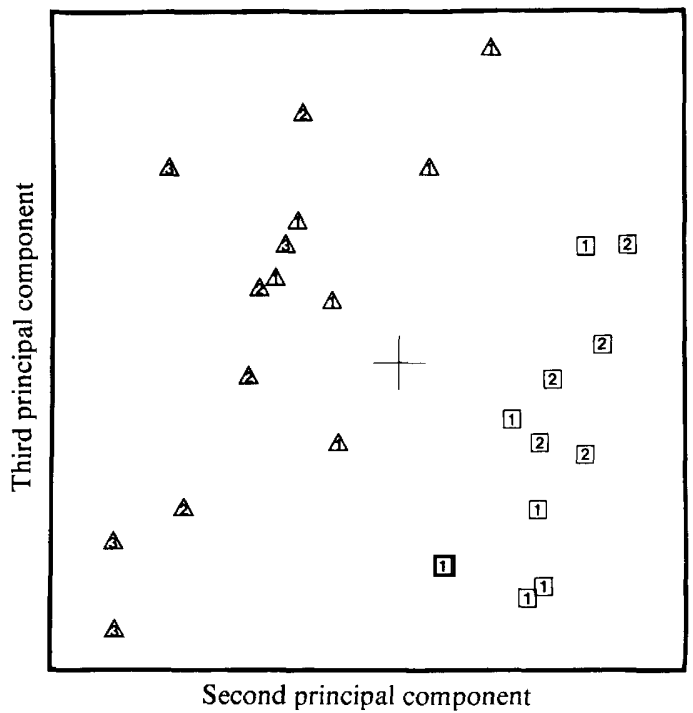

Fig. 7. The second and third principal component plotted after a principal components analysis of pyrograms of $S$. bovinus (squares) and $S$. variegatus (triangles). The numbers in the symbols refer to the fruit-body number within each species.

The model for $S$. luteus pyrograms resulted in four outliers ( $95 \%$ probability level) and the $S$. variegatus model in two (Table 1). All the $S$. bovinus pyrograms fitted well to the model. Another, perhaps more serious classification error occurs where objects are included in the wrong class models. Four pyrograms of $S$. variegatus, all from the same fruit-body $(S$. variegatus 1), were included in the $S$. luteus class model (Table 1). These were not identical to the outliers. In spite of these imperfections, the models describe the three data sets well. 


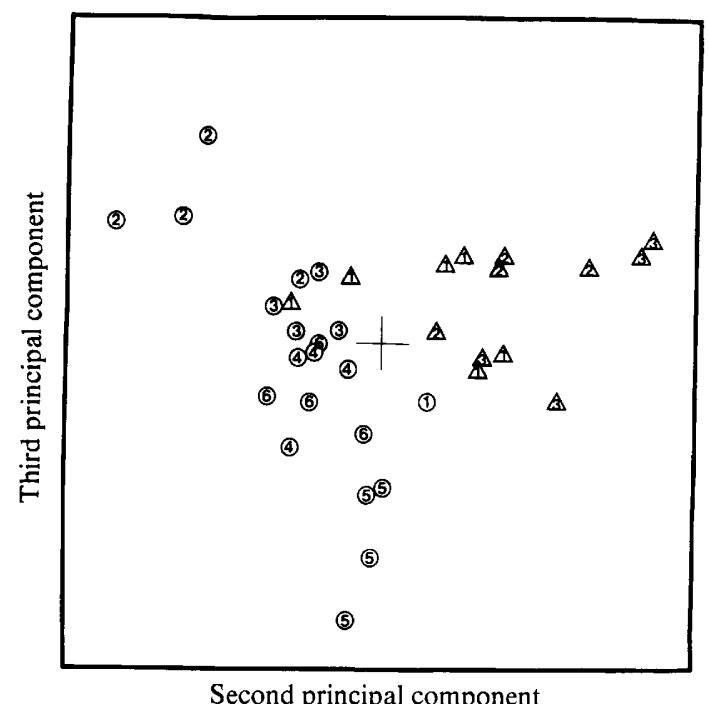

Fig. 8. The second and third principal component after principal components analysis of pyrograms of $S$. luteus (circles) and $S$. variegatus (triangles). The numbers in the symbols refer to fruit-body number within each species.

Table 1. Some characteristics of the three principal components models of pyrograms of fruit-bodies

\begin{tabular}{lccccc}
\multicolumn{1}{c}{ Model } & N & $\begin{array}{c}\text { No. of } \\
\text { components }\end{array}$ & Model-S.D. & $\begin{array}{c}\text { No. of } \\
\text { outliers }\end{array}$ & $\begin{array}{c}\text { No. of objects } \\
\text { from other classes } \\
\text { close to the model }\end{array}$ \\
S. luteus & 30 & 3 & 0.3183 & 4 & 4 \\
S. bovinus & 11 & 3 & 0.2010 & 0 & 0 \\
S. variegatus & 14 & 2 & 0.3412 & 2 & 0
\end{tabular}

Table 2. Distances $(d)$ between the three species models

$\begin{array}{lccc} & \text { S. luteus } & \text { S. bovinus } & \text { S. variegatus } \\ \text { S. luteus } & 0 & 2.49 & 1 \cdot 19 \\ \text { S. bovinus } & & 0 & 3 \cdot 32 \\ \text { S. variegatus } & & & 0\end{array}$

The statistical distances between the class models are given in Table 2. Distances below $1 \cdot 0$ are considered small or negligible (Blomquist et al., 1979 b). These calculations confirm the results indicated by the principal components plots above; that the difference between $S$. luteus and $S$. variegatus is smaller than the differences between $S$. luteus and $S$. bovinus and between $S$. variegatus and $S$. bovinus.

Separate models were also calculated for each individual fruit-body and the distances between these models were calculated (Table 3). The distance between two fruit-bodies of the same species is not always smaller than that between models of fruit-bodies of different species. 
Table 3. Distances $(d)$ between the models of individual fruit-bodies of the three Suillus species

S. luteus $1=1$

S. luteus $2=2$

S. luteus $3=3$

S. luteus $4=4$

S. luteus $5=5$

S. luteus $6=6$

S. bovinus $1=7$

S. bovinus $2=8$

S. variegatus $1=9$

S. variegatus $2=10$

$S$. variegatus $3=11$

\begin{tabular}{|c|c|c|c|c|c|c|c|c|}
\hline 2 & 3 & 4 & 5 & 6 & 7 & 8 & 9 & 10 \\
\hline $\begin{array}{c}5 \cdot 0 \\
0\end{array}$ & $\begin{array}{c}4 \cdot 8 \\
4 \cdot 2 \\
0\end{array}$ & $\begin{array}{c}6.5 \\
7 \cdot 0 \\
4.4 \\
0\end{array}$ & $\begin{array}{c}7 \cdot 1 \\
6 \cdot 9 \\
6 \cdot 4 \\
6 \cdot 8 \\
0\end{array}$ & $\begin{array}{c}3.8 \\
3.9 \\
4.4 \\
4.9 \\
5.0 \\
0\end{array}$ & $\begin{array}{r}4.7 \\
6.3 \\
6.6 \\
11.4 \\
8.7 \\
6.6 \\
0\end{array}$ & $\begin{array}{c}12 \cdot 1 \\
8 \cdot 0 \\
7 \cdot 7 \\
9 \cdot 3 \\
7 \cdot 1 \\
5 \cdot 9 \\
5 \cdot 5 \\
0\end{array}$ & $\begin{array}{c}3 \cdot 2 \\
5 \cdot 0 \\
2 \cdot 4 \\
3 \cdot 5 \\
3 \cdot 5 \\
4 \cdot 3 \\
7 \cdot 9 \\
6 \cdot 4 \\
0\end{array}$ & $\begin{array}{c}5 \cdot 1 \\
5 \cdot 0 \\
5 \cdot 3 \\
6 \cdot 1 \\
6 \cdot 9 \\
3 \cdot 6 \\
10 \cdot 1 \\
9 \cdot 4 \\
3 \cdot 5 \\
0\end{array}$ \\
\hline
\end{tabular}

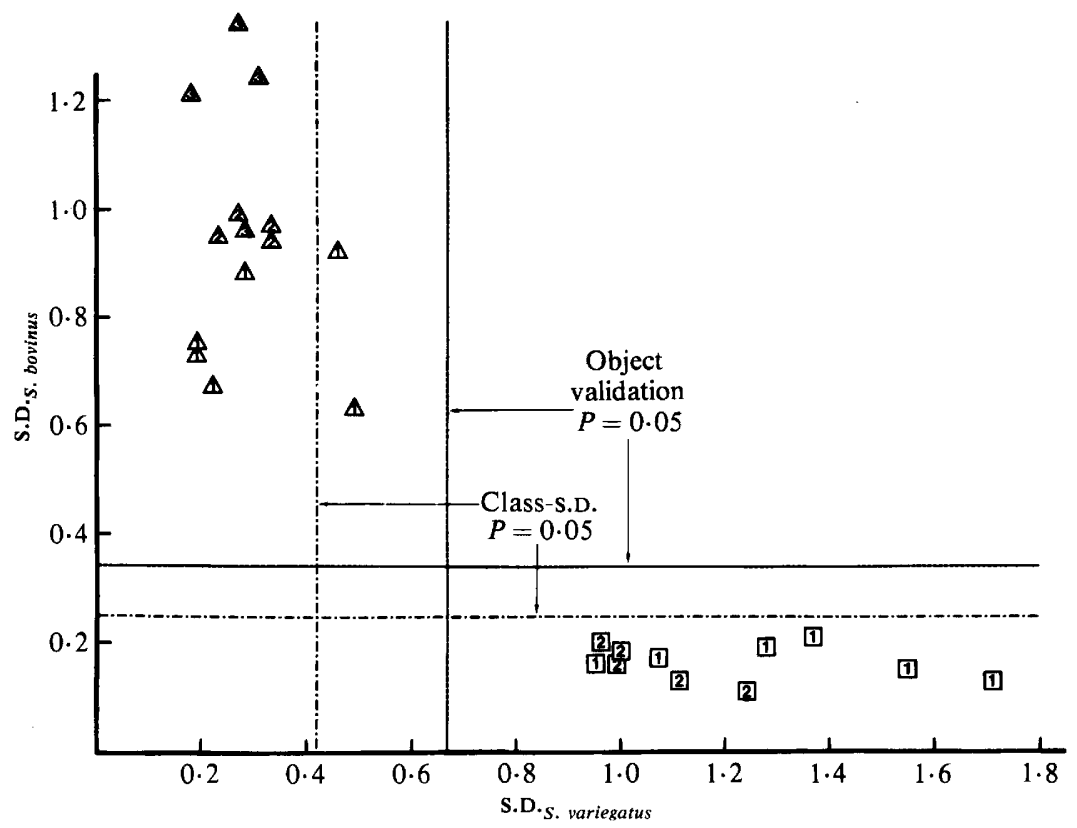

Fig. 9. Class distance plot for S. bovinus and S. variegatus. Each pyrogram was fitted to the two models, and the abscissa represents the s.D. values obtained when they were fitted to the $S$. variegatus class model and the ordinate represents the S.D. values when fitted to the $S$. bovinus class model. The confidence limits of these models are also given. Triangles, pyrograms of $S$. variegatus; squares, $S$. bovinus. The numbers in the symbols refer to fruit-body number within each species.

\section{SIMCA analysis with object validation}

The results of the object validations of the SIMCA class models as well as the normal class-S.D. values are presented in Figs 9, 10 and 11. It is clear that the class representing $S$. bovinus is significantly separated from both the $S$. variegatus (Fig. 9) and the $S$. luteus (Fig. 10 ) classes and that no pyrograms are incorrectly classified. However, the classes describing $S$. luteus and $S$. variegatus are less well separated (Fig. 11). In fact, on the $P=0.05$ level, about half of the pyrograms of $S$. luteus will also belong to $S$. variegatus and half of the $S$. variegatus pyrograms will belong to the $S$. luteus model. All fruit-bodies examined during the object classification procedure were, however, correctly classified as seen from Figs 9-11. 


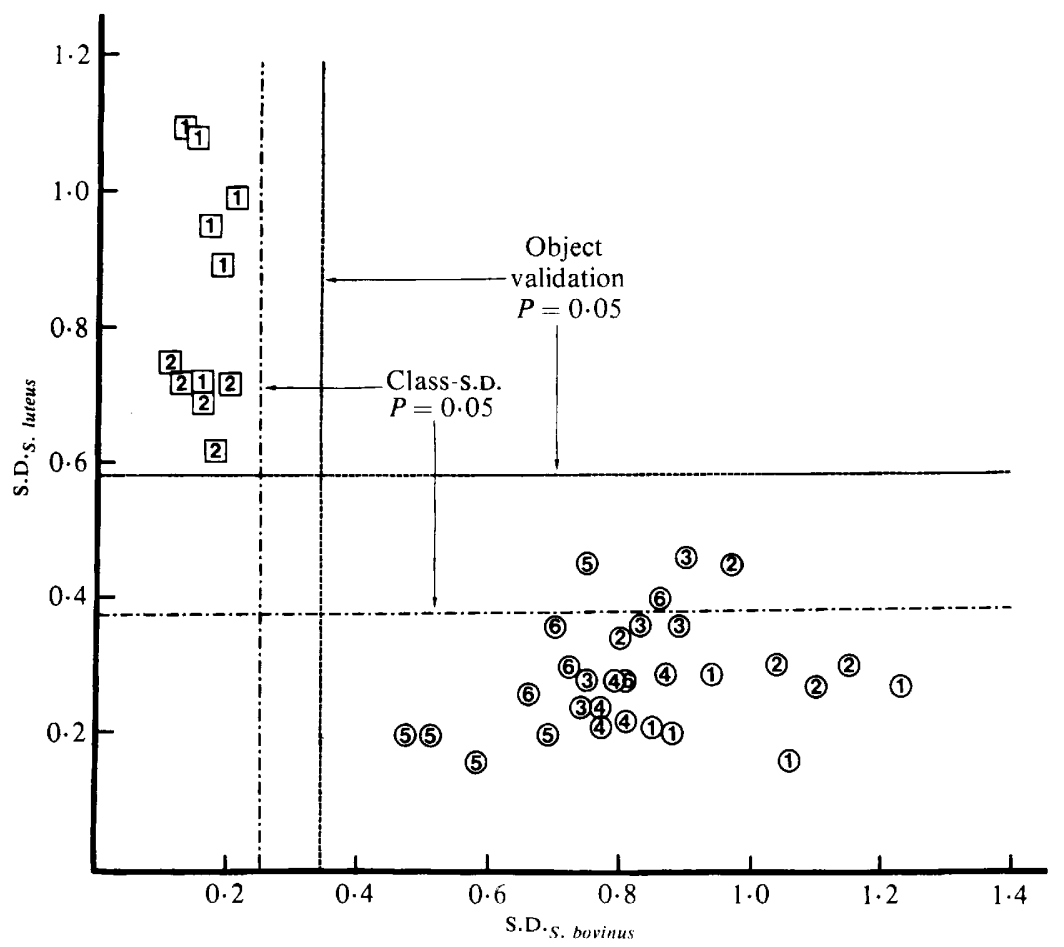

Fig. 10. Class distance plot for $S$. luteus and $S$. bovinus. The data were analysed similarly to those in Fig. 9. Circles, pyrograms of $S$. luteus: squares, $S$. bovinus. The numbers in the symbols refer to fruitbody number within each species.

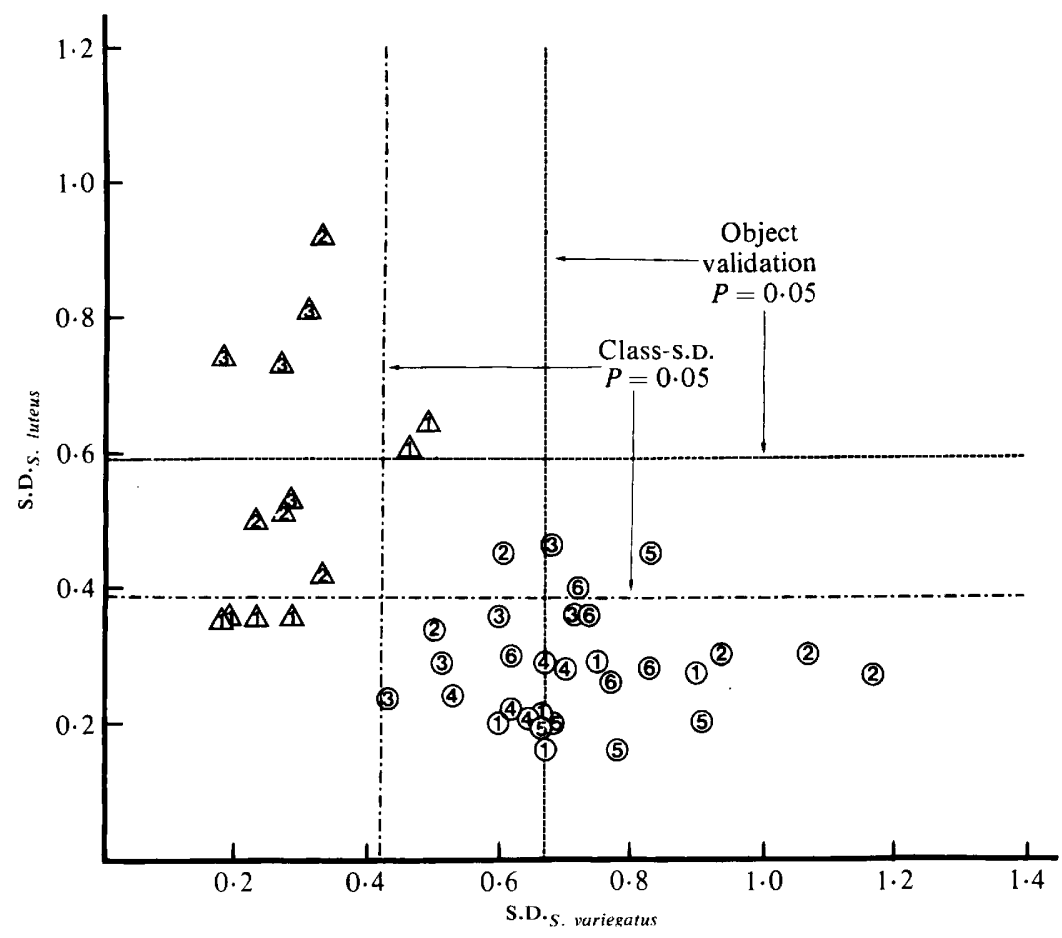

Fig. 11. Class distance plot for S. luteus and S. variegatus similar to Figs 9 and 10. 


\section{Nearest neighbour analysis}

In the nearest neighbour analysis the five nearest neighbours of all $S$. bovinus pyrograms were intra-strain or intra-species pyrograms. Thus, this species was omitted in the next analysis, which showed that two of the $S$. luteus pyrograms had $S$. variegatus pyrograms as the closest nearest neighbour.

\section{DISCUSSION}

Data produced by Py-GC are undoubtedly useful for unbiased characterization of biological material as demonstrated by many authors. Earlier, differences in specific peaks between the pyrograms of different species were used for separation (e.g. Kulik \& Vincent, 1973). By applying multivariate data analyses, more of the information can be used, and, thus, more efficient classification of the pyrograms is possible. One of the major advantages of the SIMCA analysis method used in this study, is that a SIMCA analysis tells how good or bad the classification is.

In all modelling the validation of the proposed models is a crucial step. In this study the variation between the different fruit-bodies of a species was higher than the variation between the pyrograms of one fruit-body (Figs 4-8), i.e. the pyrograms within a single fruit-body were not independent. In this situation the most unbiased procedure for model validation is to omit all the pyrograms of one fruit-body, and then recalculate the model on the basis of the remaining data and thereafter refit the omitted fruit-body pyrograms to the new model. This object validation method was used for $S$. luteus and $S$. variegatus. However, it should be remembered that this validation method, as illustrated in Figs 9, 10 and 11, gives conservative results. It might well severely underestimate the predictive power of the models.

The separation between the three fruit-bodies of $S$. variegatus and the two specimens of $S$. bovinus was also very good (significant at the $95 \%$ level), when the conservative object validation of the species models was used (Fig. 9). This was also the case for S. bovinus and the six fruit-bodies of $S$. luteus (Fig. 10). However, there were some difficulties in separating and classifying pyrograms of $S$. luteus and $S$. variegatus correctly.

In the principal components analysis illustrated in Fig. 6, six fruit-bodies of $S$. luteus were included, each represented by four pyrograms. The pyrograms of fruit-body number 1 can be found in the central lower part of the plot and they appear to cluster together. Fruit-body number 2 is in the upper left corner, fruit-body number 3 central left etc. The pyrograms from each fruit-body are thus generally rather close to each other. Doubtless, the variation between the different fruit-bodies was the variation that made separation poor between $S$. luteus and $S$. variegatus. Suillus variegatus 1 was the fruit-body of this species that appeared rather similar to $S$. luteus (Fig. 4). Figure 11 shows that the pyrograms of this particular fruit-body are difficult to classify correctly and Table 3 shows the distances to be small between this fruit-body and five of the six $S$. luteus fruit-bodies.

These results indicate that $S$. luteus and $S$. variegatus might have been better described as one class. Thus, a SIMCA class model based on both the $S$. luteus and the $S$. variegatus pyrograms was calculated. However, this model showed a low predictive value (high confidence limits). In spite of these wider confidence limits, the number of outliers was six. Thus, the $S$. luteus and $S$. variegatus pyrograms were difficult to model together, suggesting that these species are distinct taxa in spite of the difficulties in separating their pyrograms. This is in accordance with classical taxonomy; Singer $(1965,1975)$ classified $S$. luteus as belonging to the section Suillus (subsection Angustiporini Sing.; Singer, 1965) and both $S$. variegatus and $S$. bovinus to section Fungosi (subsections Stenoporini Sing. respective Euryporini Sing.; Singer, 1965). The taxonomic position of these species was recently confirmed by Pegler \& Young (1981).

The distances between the different classes (Tables 2 and 3 ) could possibly be used for taxonomic purposes. The intra-species distances in $S$. variegatus (mean $=3 \cdot 3$ ) with one 
exception are smaller than the inter-species distances (mean $=6.4$ ). This is also true for $S$. bovinus (with an intra-species mean of 5.5 as compared to 8.6). However, the difference between the intra-species distances (mean 5.4) and the inter-species distances (mean 6.2) is considerably smaller in $S$. luteus, and in this species there are also many examples of higher distance values within the species compared to the inter-species values. Brosseau \& Carmichael (1978) in their Py-GC study of Arthroderma tuberculatum and three other related fungi, clustered their pyrograms with a computer program called TAXMAP, and they also calculated distances between the clusters. They stated that distances within a cluster were approximately the same as the distances between the clusters, and also that the distances were roughly the same between all clusters. It thus appears that we now have a somewhat more promising picture, but it is still doubtful whether these distances have any taxonomic significance.

The organisms used in this study represented three different, but closely related basidiomycete species. In all, 11 different strains were used. Further, the fruit-bodies were produced under natural conditions in the field. Thus, the six different fruit-bodies of $S$. luteus were produced by different mycelia growing in rather heterogeneous, podzolic soils under different environmental conditions. It is well established that organisms grown under different environmental conditions might differ considerably in chemical composition (Foster, 1949). This might also result in different pyrogram patterns (Oxborrow et al., 1977; Blomquist et al., $1979 a$; Gutteridge \& Norris, 1980). These facts might explain the rather wide variability of the fruit-bodies within one fungal species in the present study. Other uncontrolled factors were the age of the fruit-bodies and possible secondary infections. It should also be noticed that no pyrograms were excluded as outliers in the calculation of the models. Undoubtedly, a much better separation of the models would have been obtained by excluding a few awkward pyrograms. However, the models would then lose in general predictive value.

The fact that gas chromatograph columns may change their separation properties with ageing (French et al., 1980) also introduces noise into the data. Such noise may of course severely influence the classification procedure. However, most classification systems have a relative or subjective component which has resulted in the need of standards, like type cultures. By introduction of standards into the Py-GC runs and by using these standards for numerical corrections of the test samples, this noise can probably be considerably reduced. Considering the problem of great biological and some analytical heterogeneity of the material used, the conclusion must be that the attempts to separate and classify closely related fruit-bodies by means of Py-GC combined with SIMCA pattern recognition were reasonably successful. Further studies will show if the classification can be improved.

The gas chromatograph used was borrowed from the Laboratory of Ecological Chemistry, University of Lund. and we thank Dr G. Odham for this generosity. The study was supported by grants from the Swedish Natural Science Research Council and the Swedish Council for Forestry and Agricultural Research.

\section{REFERENCES}

Abbey, L. E., Highsmith, A. K., Moran, T. F. \& REINER, E. J. (1981). Differentiation and characterization of Klebsiella pneumoniae strains by pyrolysis-gas-liquid chromatography-mass spectrometry. Journal of Clinical Microbiology 13, 313319.

Albano, C., Blomquist, G., Dunn III. W., Edlund, U., Eliasson, B., Johansson, E., NordÉn, B., Sjöström, M., Söderström, B. \& Wold, S. (1980). Characterization and classification based on multivariate data analysis. In The 27th International Congress of Pure and Applied Chemistry, pp.
377-386. Edited by A. Varmavuori. Oxford: Pergamon Press.

Blomquist, G., Johansson, E., Söderström, B. \& WoLD, S. $(1979 a)$. Data analysis of pyrolysischromatograms by means of SIMCA-pattern recognition. Journal of Analytical and Applied Pyrolysis 1, 53-65.

Blomquist, C., Johansson, E., Söderström, B. \& WoLd, S. $(1979 b)$. Classification of fungi by means of pyrolysis-gas chromatography-pattern recognition. Journal of Chromatography 173, 19-32.

Blomquist, G., Johansson, E., Söderström, B. \& 
WoLD, S. $(1979 c)$. Reproducibility of pyrolysis-gas chromatograms of the mould Penicillium brevicompactum. Journal of Chromatography 173, 7-17.

Brosseau, J. D. \& Carmichael, J. W. (1978). Pyrolysis gas liquid chromatography applied to a study of variation in Arthroderma tuberculatum. Mycopathologia 63, 67-79.

DominIK, T. (1959). Synopsis of a new classification of the ectotrophic mycorrhizae established on morphological and anatomical characteristics. Mycopathologia et mycologia applicata 11, 359-367.

DruCKer, D. B. (1981). Microbiological Applications of Gas Chromatography. Cambridge: Cambridge University Press.

Emswiler, B. S. \& Kotula, A. W. (1978). Differentiation of Salmonella serotypes by pyrolysis-gas liquid chromatography of cell fragments. Applied and Environmental Microbiology 35, 97-104.

Foster, J. W. (1949). Chemical Activities of Fungi. New York: Academic Press.

French, G. L., Gutteridge, C. S. \& Phillips, I. (1980). Pyrolysis gas chromatography of Pseudomonas and Acinetobacter species. Journal of Applied Bacteriology 49, 505-516.

Gunasekaran, M., Weber, D. J. \& Hess, W. M. (1979). Differentiation of races of Tilletia caries and $T$. foetida by pyrolysis-gas-liquid chromatography. Mycologia 71, 1066-1071.

GutTERIDGE, C. S. \& NorRIS, J. R. (1980). Effect of different growth conditions on the discrimination of three bacteria by pyrolysis gas liquid chromatography. Applied and Environmental Microbiology 40, 462-465.

GutTeridge, C. S., MACKey, B. M. \& Norris, J. R. (1980). A pyrolysis gas liquid chromatography study of Clostridium botulinum and related organisms. Journal of Applied Bacteriology 49, 165-174.

Jones, C. E. R. \& Cramers, C. A. (editors) (1977). Analytical Pyrolysis. Amsterdam: Elsevier Publishing Co.

Kulik, M. M. \& Vincent, P. G. (1973). Pyrolysis gas-liquid chromatography of fungi: observations on variability among nine Penicillium species of the section Asymetrica, subsection Fasciculata. Mycopathologia et mycologia applicata 51, 1-18.

MACFIE, H. J. H., GutTeridge, C. S. \& Norris, J. R. (1978). Use of canonical variates analysis in differentiation of bacteria by pyrolysis gas-liquid chromatography. Journal of General Microbiology 104, 67-74.

Marais, L. J. \& Kotzé, J. M. (1979). Pyrolysis gas liquid chromatographic differentiation of plant virus strains in situ. Zeitschrift für Pflanzenkrankheiten Pflanzenpathologie und Pflanzenschutz 86, 569576.
O'Donnell, A. G., Macfie, H. J. H. \& Norris, J. R. (1980). An investigation of the relationship between Bacillus cereus, Bacillus thuringiensis and Bacillus mycoides using pyrolysis gas-liquid chromatography. Journal of General Microbiology 119, 189-194.

Oxborrow, G. S., Fields, N. D. \& Puelo, J. R. (1977). Pyrolysis gas-liquid chromatography of the genus Bacillus: effect of growth media on pyrochromatogram reproducibility. Applied and Environmental Microbiology 33, 865-870.

Pegler, D. N. \& Young, T. W. K. (1981). A natural arrangement of boletales, with reference to spore morphology. Transactions of the British Mycological Society 76, 103-146.

Seviour, R. J., Chilvers, G. A. \& Crow, W. D. (1974). Characterization of eucalypt mycorrhizas by pyrolysis-gas chromatography. New Phytologist 73, 321-332.

Singer, R. (1965). Die Röhrlinge. Teil I. Die Boletaceae. Bad Heilbrunn (Obb.), Germany: Verlag Julius Klinkhardt.

Singer, R. (1975). The Agaricales in Modern Taxonomy, 3rd edn. Vaduz, Lichtenstein: J. Cramer Verlag.

SNeAth, P. H. A. \& Sokal, R. R. (1973). Numerical Taxonomy. San Francisco: W. H. Freeman.

Stern, N. J., Kotula, A. W. \& Pierson, M. D. (1979). Differentiation of selected Enterobacteriaceae by pyrolysis gas-liquid chromatography. Applied and Environmental Microbiology 38, 1098-1102.

Stern, N. J., Kotula, A. W. \& Pierson, M. D. (1980). Virulence prediction of Yersinia enterocolitica by pyrolysis gas liquid chromatography. Applied and Environmental Microbiology 40, 646651.

Symuleski, R. A. \& Wetzel, D. M. (1979). Applicability of pyrolysis/gas-liquid chromatography for the identification of bacteria in sewage treatment plant effluent. Environmental Science and Technology 13, 1124-1130.

Wold, S. (1978). Cross-validatory estimation of the number of components in factor and principal components models. Technometrics 20, 397-405.

WoLD, S. \& SJöSTRöM, M. (1977). SIMCA: a method for analysing chemical data in terms of similarity and analogy. In ACS Symposium Series, No. 52. Chemometrics: Theory and Application, pp. 243282. Edited by B. R. Kowalski. Washington, D.C.: American Chemical Society.

$Z_{\text {AK, B. (1973). Classification of ectomycorrhizae. In }}$ Ectomycorrhizae. Their Ecology and Physiology. pp. 43-78. Edited by G. C. Marks \& T. T. Kozlowski. New York: Academic Press. 